\title{
Puréed Foods, Thickened Beverages, and Water Needs ${ }^{1}$
}

\author{
Wendy J. Dahl ${ }^{2}$
}

Adequate water intake may be a problem for some people who have trouble swallowing, particularly for those who have difficulty swallowing thin liquids. Examples of thin liquids include water, milk, coffee, tea, and most fruit juices. Normally, these beverages contribute significantly to total water intake and serve to prevent dehydration. However, thin liquids move very quickly during the swallowing process, and those with delayed or uncoordinated swallowing may have problems swallowing them. Some of the liquid may get into the lungs and cause coughing and possibly choking. Thickened liquids are often recommended for individuals who have problems swallowing thin liquids.

\section{Thickened liquids}

Thickened liquids are prepared by adding starch or gum thickeners to thin liquids. The recommended thickness for liquids is specific to the individual with a swallowing problem. Common consistencies are nectar, honey, and pudding. Nectar-like liquids can be sipped through a straw and drip slowly off of a spoon. Examples of nectar-like thickness include eggnog and tomato juice. Honey-like liquids can be sipped from a cup or eaten with a spoon. An example of honey-like thickness is a thick cream soup. Pudding-like liquids can be eaten with a spoon and hold their shape when on a spoon. Examples include yogurt and milk pudding.

Juice, milk, water, and even coffee can be thickened. Prethickened beverages are available commercially, or they can be prepared with various commercial thickeners. Directions

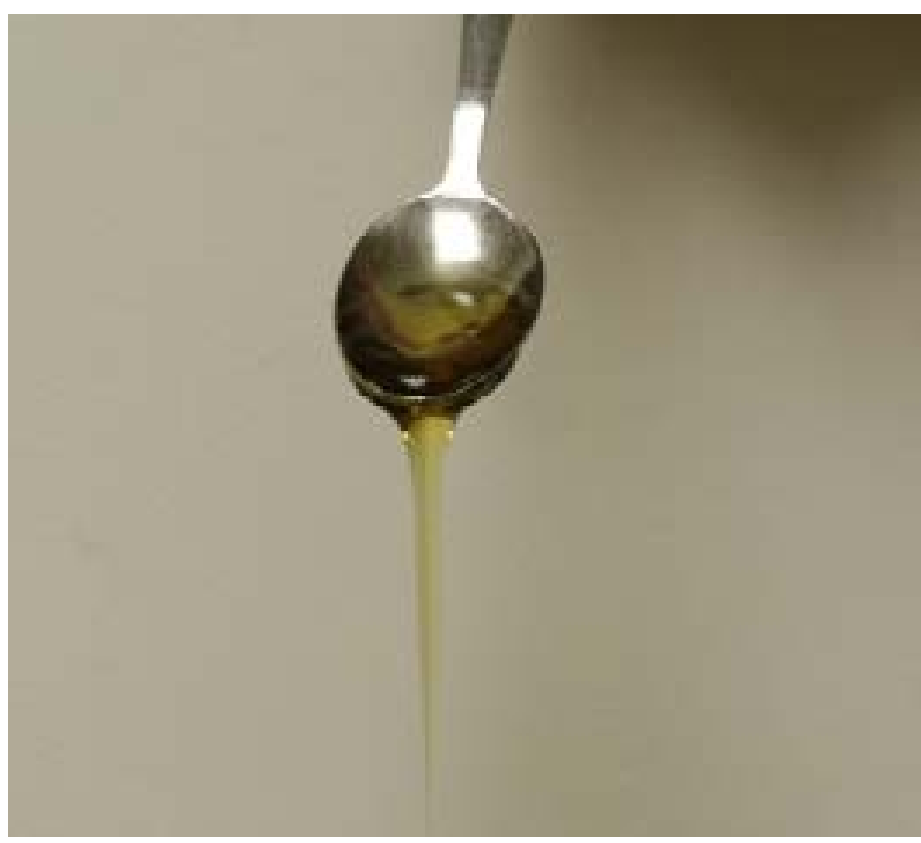

Figure 1. Nectar Credits: UF/IFAS

for preparing a thickened beverage depend on the type of thickener used. Product-specific preparation guides are available for nectar, honey, and pudding consistencies. However, as individual patient needs differ, it is important to consult with health professionals and create standardized recipes for each food and beverage for each individual with a swallowing problem (also known as dysphagia). Following a recipe produces a consistent thickness. This is especially important if more than one person is involved in the day-to-day preparation of thickened liquids. Examples of thickened liquid preparation guides are as follows:

1. This document is FSHN13-01, one of a series of the Food Science and Human Nutrition Department, Florida Cooperative Extension Service, Institute of Food and Agricultural Sciences, University of Florida. Original publication date March 2013. Visit the EDIS website at http://edis.ifas.ufl.edu.

2. Wendy J. Dahl, assistant professor, Food Science and Human Nutrition Department, University of Florida Institute of Food and Agricultural Sciences, Gainesville, FL 32611.

The use of trade names in this publication is solely for the purpose of providing specific information. UF/IFAS does not guarantee or warranty the products named, and references to them in this publication do not signify our approval to the exclusion of other products of suitable composition. 


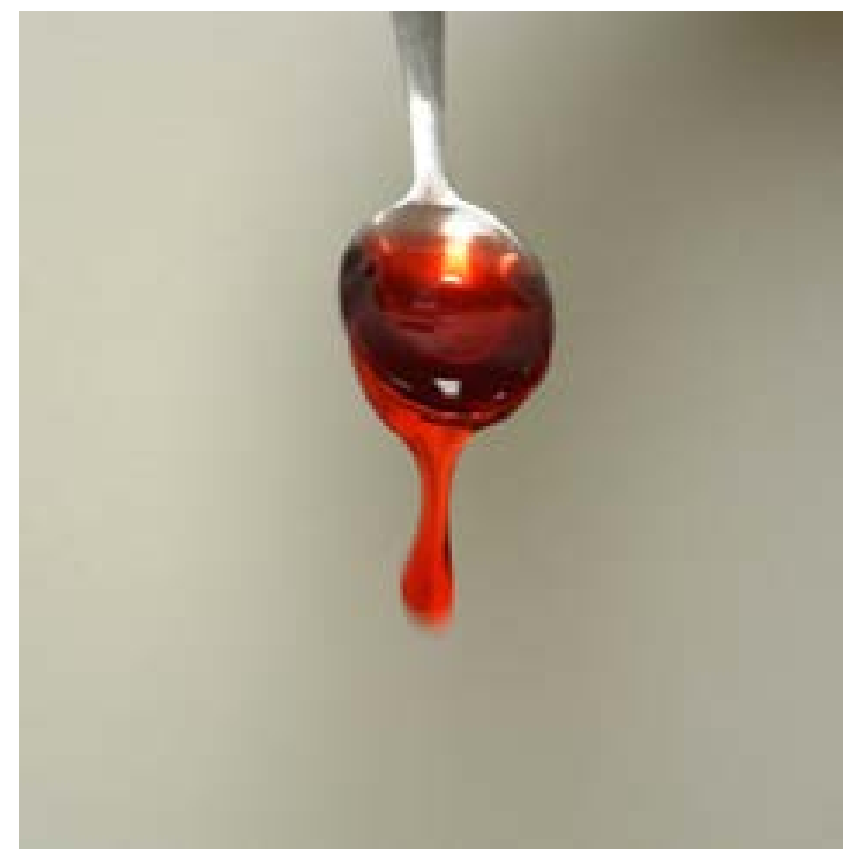

Figure 2. Honey Credits: UF/IFAS

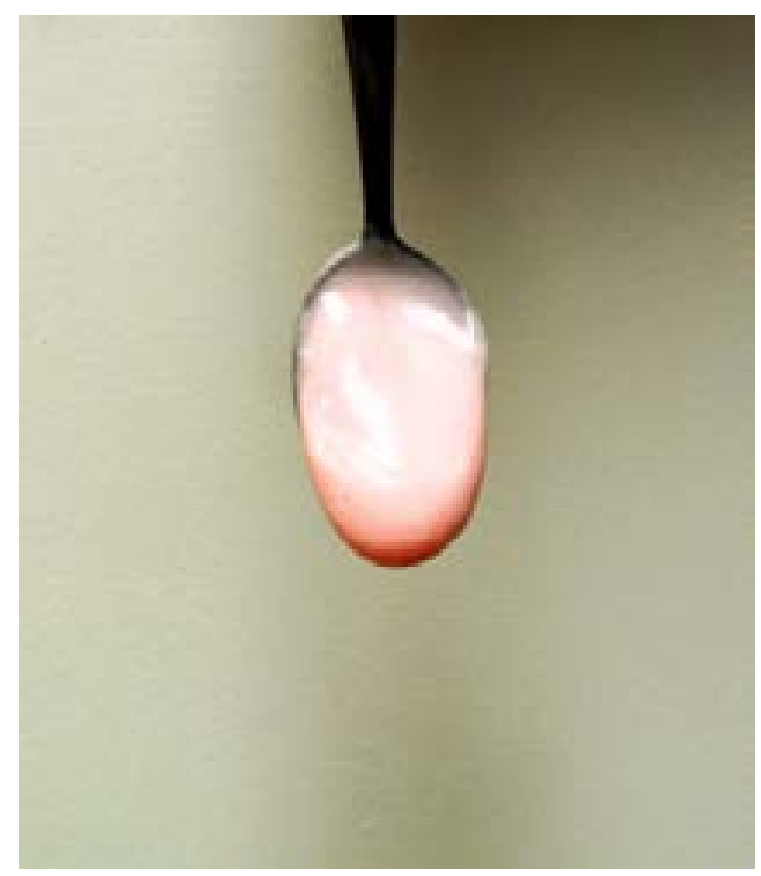

Figure 3. Pudding Credits: UF/IFAS

Thickening with starch

http://www.thickitretail.com/Portals/0/TIR-001-ThickItUsageChart.pdf

http://www.hormelhealthlabs.com/1coltemplate. aspx?page=te_mixing_chart

Thickening with gums

http://www.simplythick.com

/0C5F070C-C34F-2ED0-B55A3FDDE04ABEE4

\section{How much water do foods contribute?}

Although thickened beverages are served to ensure that individuals with certain swallowing problems receive adequate hydration, it is important to note that foods also provide water and, therefore, contribute to hydration. Many people who require thickened beverages also may require puréed foods. Puréed foods are particularly high in water, typically $70 \%-90 \%$. Puréed foods are not only sources of water, but they may also provide more nutrients and may be more acceptable than thickened beverages.

Let's consider thickened milk. Fluid milk with $2 \%$ fat contains about $89 \%$ water. This means that an $8 \mathrm{oz}$ serving ( 1 cup or $250 \mathrm{~mL}$ ) of milk provides about $7 \mathrm{oz}(220 \mathrm{~mL}$ ) of water. The addition of starch thickener to the milk has only a small effect on the percentage of water, but it may have a significant effect on taste and acceptability because starch thickeners tend to suppress flavor. Alternatively, reducedfat, flavored yogurts contain about $85 \%-87 \%$ water, so an $8 \mathrm{oz}$ serving also provides about $7 \mathrm{oz}(220 \mathrm{~mL})$ of water. As yogurts are naturally thick, it is not necessary to add a thickener to ease swallowing. Yogurts offer not only acceptable flavor but also reliable consistency, whereas the consistency of thickened milk may vary with each preparation. It is important to note that water can be provided through a variety of commercially available, flavored yogurts instead of thickened milk. Choose yogurts with added vitamin D to ensure optimal nutrition. Providing water through usual foods such as yogurt is a good option for those who find thickened milk less acceptable.

Another example to consider is thickened juice. Apple juice is considered a beverage, but does it provide more water than applesauce? In fact, both apple juice and applesauce contain about $88 \%$ water! A $4 \mathrm{oz}(125 \mathrm{~mL})$ portion of either provides about $3 \frac{1}{2} \mathrm{Oz}(110 \mathrm{~mL})$ of water. The preparation of thickened apple juice requires the addition of a thickener such as starch, whereas applesauce is already thick because of its fiber content. A disadvantage of thickened apple juice is that it provides very little fiber. Carefully consider the need for providing thickened fruit juices versus fruit purées. While both provide water and other nutrients, only the fruit purées provide a significant amount of fiber. Table 1 lists the water and energy contents of common puréed foods and beverages.

The sample menu below meets the MyPlate guidelines (ChooseMyPlate.gov) (see also MyPlate for Dysphagia [http://edis.ifas.ufl.edu/fs207]). It provides about $1800 \mathrm{~mL}$ of water and $1800 \mathrm{kcal}$ given typical portion sizes, meeting 
Table 1. Water content of common puréed texture foods and beverages

\begin{tabular}{|c|c|c|c|}
\hline Dairy & Serving size & $\begin{array}{l}\text { Water } \\
\text { content }\end{array}$ & $\begin{array}{c}\text { Energy } \\
\text { (kcal) }\end{array}$ \\
\hline Milk - 2\% & 1 cup $(250 \mathrm{~mL})$ & $89 \%$ & 122 \\
\hline Chocolate milk - reduced fat & 1 cup $(250 \mathrm{~mL})$ & $82 \%$ & 190 \\
\hline Yogurt, plain, low fat & $3 / 4$ cup $(375 \mathrm{~mL})$ & $85 \%$ & 116 \\
\hline Puréed cottage cheese - $2 \%$ & $1 / 2$ cup $(125 \mathrm{~mL})$ & $81 \%$ & 110 \\
\hline Pudding, vanilla, ready-to-eat & $1 / 2$ cup $(125 \mathrm{~mL})$ & $72 \%$ & 143 \\
\hline \multicolumn{4}{|l|}{ Vegetables } \\
\hline Beets - canned, puréed & $1 / 2$ cup $(125 \mathrm{~mL})$ & $91 \%$ & 37 \\
\hline Carrots - cooked, puréed & $1 / 2$ cup $(125 \mathrm{~mL})$ & $90 \%$ & 36 \\
\hline Creamed corn - canned, puréed & $1 / 2$ cup $(125 \mathrm{~mL})$ & $79 \%$ & 92 \\
\hline Peas - cooked, puréed & $1 / 2$ cup $(125 \mathrm{~mL})$ & $82 \%$ & 60 \\
\hline Mashed potatoes with butter and milk & $1 / 2$ cup $(125 \mathrm{~mL})$ & $76 \%$ & 119 \\
\hline Sweet potato - canned, mashed & $1 / 2$ cup $(125 \mathrm{~mL})$ & $74 \%$ & 129 \\
\hline Squash - cooked, mashed & $1 / 2$ cup $(125 \mathrm{~mL})$ & $90 \%$ & 42 \\
\hline \multicolumn{4}{|l|}{ Fruits } \\
\hline Apple juice & $3 / 4$ cup $(375 \mathrm{~mL})$ & $88 \%$ & 86 \\
\hline Applesauce - unsweetened & $1 / 2$ cup $(125 \mathrm{~mL})$ & $88 \%$ & 51 \\
\hline Avocado - puréed & $1 / 4$ cup $(60 \mathrm{~mL})$ & $83 \%$ & 92 \\
\hline Banana - mashed & $1 / 2$ cup $(125 \mathrm{~mL})$ & $84 \%$ & 112 \\
\hline Orange juice & $3 / 4$ cup $(375 \mathrm{~mL})$ & $88 \%$ & 92 \\
\hline Peach purée & $1 / 2$ cup $(125 \mathrm{~mL})$ & $89 \%$ & 88 \\
\hline \multicolumn{4}{|l|}{ Protein foods } \\
\hline Baked beans - vegetarian, canned, puréed & $1 / 2$ cup $(125 \mathrm{~mL})$ & $72 \%$ & 119 \\
\hline Chicken - canned & $1 / 2$ cup $(125 \mathrm{~mL})$ & $67 \%$ & 187 \\
\hline Refried beans - puréed & $1 / 2$ cup $(125 \mathrm{~mL})$ & $78 \%$ & 108 \\
\hline Egg - scrambled & $1 / 2$ cup $(125 \mathrm{~mL})$ & $76 \%$ & 164 \\
\hline Hummus & $1 / 4 \operatorname{cup}(60 \mathrm{~mL})$ & $67 \%$ & 102 \\
\hline Salmon - canned & $3 \mathrm{oz}(85 \mathrm{~g})$ & $71 \%$ & 117 \\
\hline Tuna - canned & $3 \mathrm{oz}(85 \mathrm{~g})$ & $78 \%$ & 73 \\
\hline Tofu - soft & $1 / 2$ cup $(125 \mathrm{~mL})$ & $87 \%$ & 76 \\
\hline \multicolumn{4}{|l|}{ Grains } \\
\hline Bread - puréed & $1 / 3$ cup $(85 \mathrm{~mL})$ & $49 \%$ & 80 \\
\hline Cream of wheat porridge & 1 cup $(250 \mathrm{~mL})$ & $88 \%$ & 132 \\
\hline Corn grits & 1 cup $(250 \mathrm{~mL})$ & $83 \%$ & 182 \\
\hline Oatmeal porridge & 1 cup (250 mL) & $84 \%$ & 146 \\
\hline Pasta - puréed & $1 / 2$ cup $(125 \mathrm{~mL})$ & $86 \%$ & 50 \\
\hline
\end{tabular}


the minimum fluid requirements of $1 \mathrm{~mL} / \mathrm{kcal}$ (Holiday and Seager 1957). The addition of beverages (thickened if needed) to the menu would provide more water. Although the recommended Adequate Intake (AI) of water for healthy, active women is $2700 \mathrm{~mL}$ per day and $3700 \mathrm{~mL}$ per day for healthy, active men, individuals with swallowing problems may be much less active and may live in comfortable, temperature-controlled environments, and thus may have lower fluid requirements.

\section{Sample Puréed Menu}

\section{Breakfast}

Oatmeal with Milk and Brown Sugar

Scrambled Eggs

Blueberry Yogurt

Banana

\section{Lunch}

Salmon Salad

Puréed Bread

Creamed Spinach Purée

Puréed Peaches

Snack

Cottage Cheese with Pears

Light Lemonade (thickened if required)

\author{
Dinner \\ Refried Beans \\ Corn Grits \\ Avocado and Salsa Purée \\ Vegetable Cocktail (thickened if required) \\ Vanilla Pudding

\section{Evening Snack} \\ Peanut Butter and Jelly Bread Purée \\ Fruit Smoothie
}

\section{Where can I get more information?}

The Family and Consumer Sciences (FCS) agent at your county Extension office may have more written information and nutrition classes for you to attend. Also, a registered dietitian (RD) can provide reliable information.

\section{References}

Holiday, M. A., and W. E. Seager. 1957. “The Maintenance Need for Water in Parenteral Fluid Therapy." Pediatrics 19: 823.

USDA (United States Department of Agriculture). n. d. "National Nutrient Database for Standard Reference." Accessed December 28, 2012. http://ndb.nal.usda.gov/. 